\title{
A licitude civil da prática da ortotanásia por médico em respeito à vontade livre do paciente
}

Maria Luiza Monteiro da Cruz ${ }^{1}$, Reinaldo Ayer de Oliveira ${ }^{2}$

\section{Resumo}

Por meio de interpretação constitucional baseada no princípio fundamental da dignidade da pessoa humana e no direito à vida, entende-se que a Constituição Federal protege o direito à morte digna, enquanto inexiste norma federal que disponha sobre o tema. Considerando as questões sociais, jurídicas e filosóficas que envolvem a morte digna, a lacuna normativa gera insegurança jurídica manifesta no temor dos médicos de sofrer punição judicial pela prática da ortotanásia. Assim, o trabalho propõe-se a analisar a responsabilização civil do médico que pratica a ortotanásia. Para tanto, foram conceituadas a morte digna, sua compreensão ética e jurídica, definindo-se, então, os conceitos relacionados à distanásia, suicídio assistido, eutanásia e ortotanásia. Verificou-se que o médico que deixa de praticar a ortotanásia, quando eleita pelo paciente como seu tratamento, comete ato ilícito pelo qual pode ser responsabilizado civilmente.

Palavras-chave: Responsabilidade civil. Ética médica. Morte com dignidade.

\section{Resumen}

\section{La legalidad civil de la práctica de ortotanasia por el médico con respecto a libre voluntad del paciente}

A través de la interpretación constitucional basada en el principio fundamental de la dignidad de la persona humana y en el derecho a la vida, se entiende que la Constitución Federal protege el derecho a una muerte digna, aunque no exista una norma federal que regule sobre este tema. Teniendo en cuenta los aspectos sociales, jurídicos y filosóficos que involucra la muerte digna, la brecha normativa genera inseguridad jurídica que se manifiesta en el temor de los médicos de sufrir sanciones judiciales por la práctica de la ortotanasia. Así, este trabajo tiene como propósito analizar la responsabilidad civil del médico que practica la ortotanasia. Para ello, fue conceptualizada la muerte digna, su comprensión ética y jurídica; definiéndose entonces, los conceptos relacionados a la distanasia, suicidio asistido, eutanasia y ortotanasia. Se constató que el médico que deja de practicar la ortotanasia cuando es elegida por el paciente como su tratamiento, comete un acto ilícito por el cual puede ser responsabilizado civilmente.

Palabras-clave: Responsabilidad civil. Ética médica. Derecho a morir.

\section{Abstract}

\section{The civil legality of the practice of orthothanasia by physicians regarding the patient's free will}

By constitutional interpretation based on the fundamental principle of human dignity as well as on the right to life, it is understood that the Federal Constitution ensures the right to die with dignity. However, there is no federal law regulating that right. Considering the social, juridical and philosophical issues involving dignified death, the normative gap generates legal uncertainty, which is expressed on the fear physicians have of suffering judicial sanctions for practicing orthothanasia. Therefore, this work proposes to analyze the damage liability of the medical doctor who practices orthothanasia. To that point, dignified death was conceptualized in its ethical and juridical comprehension, and then the concepts of dysthanasia, assisted suicide, euthanasia and orthothanasia were defined. It was verified that the physicians who does not practice orthothanasia, whenever elected by the patient as their treatment, perpetrates an illicit action for which they may be held liable. Key words: Damage liability. Ethics, medical. Right to die.

1. Graduada ml.monteirodacruz@gmail.com 2. Doutor rayer@usp.br - Universidade de São Paulo (USP), São Paulo/SP, Brasil.

\section{Correspondência}

Maria Luiza Monteiro da Cruz - Alameda Itu, 483, apt 92 Cerqueira César CEP 01421-000. São Paulo/SP, Brasil. 
Em 2006, o Conselho Federal de Medicina (CFM) publicou a Resolução $1.805^{1}$, que em observância ao princípio fundamental da dignidade humana dispõe sobre a morte digna. Apesar desse avanço, em maio de 2007 o Ministério Público Federal (MPF) ajuizou a Ação Civil Pública 2007.34.00.014809-3 requerendo, alternativamente, a nulidade da resolução ou que fossem definidos os critérios para a prática da ortotanásia ${ }^{2}$.

Pleiteando a improcedência da ação foi apresentado parecer que demonstrou, com primazia, a definição dos conceitos de ortotanásia, eutanásia e distanásia, permitindo melhor compreensão do texto da resolução ${ }^{2}$. Se compreende eutanásia como a provocação da morte de paciente em fase terminal de vida ou acometido por doença incurável, praticada por terceiro movido por sentimento de piedade; distanásia, como o prolongamento artificial do estado de degenerescência ${ }^{2}$ praticado pelo médico por meio de tratamentos extraordinários; e ortotanásia como a não intervenção no desenvolvimento da morte natural de pacientes em fase terminal de vida, quando a morte é iminente e inevitável ${ }^{2}$. Com a adoção dos fundamentos desse parecer, o magistrado julgou a Ação Civil Pública improcedente.

Este trabalho pretende demonstrar que a morte digna revela, como bem afirmou Oliveira, dilemas não apenas de ordem jurídica, como de cunho religioso, social e moral ${ }^{2}$ - fato que tende a turvar as linhas que distinguem conceitos relacionados à terminalidade da vida. Daí a necessidade de delinear os termos atinentes, o que torna possível identificar as condutas que diferenciam a ortotanásia da eutanásia, por exemplo, distinção altamente relevante para que uma conduta lícita não seja taxada como criminosa.

Por meio de interpretação constitucional baseada no princípio fundamental da dignidade da pessoa humana, bem como no direito à vida, é possível afirmar que a Constituição Federal protege, de maneira implícita, o direito à morte digna. Entretanto, o sistema jurídico brasileiro não possui norma federal que disponha sobre o tema. Considerando que a morte digna envolve questões polêmicas dos pontos de vista jurídico, religioso, social, médico e filosófico cabe dizer que a lacuna normativa gera insegurança jurídica relevante, manifesta no temor dos médicos de sofrer punição judicial pela prática da ortotanásia - mesmo quando sabem que a prática é, de fato, lícita.

Assim, o presente estudo pretende analisar, sob a ótica do direito civil, os elementos essenciais à responsabilidade médica para verificar se a conduta do médico que pratica a ortotanásia é passível de responsabilização na seara jurídica.

\section{Morte digna como valor e como direito}

Atualmente, tem sido destacada a relevância da comunicação e do respeito às vontades do paciente para a melhora de seu bem-estar ao fim da vida. Essa mudança de paradigma enfatiza a transição do foco da assistência médica da cura para o cuidado ${ }^{3}$.

No Brasil, o indivíduo no fim da vida pouco sabe a respeito de seu direito à morte digna e o próprio CFM reconhece que aquele acometido por doença incurável em fase terminal é frequentemente tratado com métodos terapêuticos inócuos ao combate da doença, capazes de adiar a morte às custas da diminuição da qualidade de vida do paciente ${ }^{1}$.

A morte digna deve ser fruto de uma decisão consciente e informada do paciente. Neste quadro, cabe ao médico respeitar a vontade do paciente que escolhe evitar tratamentos extraordinários - que apesar de prolongarem a quantidade de vida, prejudicam sua qualidade. A partir deste ponto a responsabilidade civil do médico pela morte do paciente passa a ser questionada, em especial a omissão caracterizada como negligência no ato médico. Assim, cabe indagar: o médico que, seguindo a vontade de seu paciente, não realiza tratamento extraordinário pode vir a ser responsabilizado por sua morte?

Para responder este questionamento faz-se preciso acrescentar à definição ética de morte digna o cuidado paliativo, que visa disponibilizar cuidados ao paciente em fase terminal, oferecendo-lhe conforto e alívio da dor. Segundo a Organização Mundial da Saúde (OMS), cuidados paliativos consistem em uma abordagem que visa melhorar a qualidade de vida dos doentes e de suas famílias, que enfrentam problemas decorrentes de uma doença incurável com prognóstico limitado e/ou doença grave (que ameaça a vida), através da prevenção e alívio do sofrimento, com recurso à identificação precoce, avaliação adequada e tratamento rigoroso dos problemas não só físicos, como a dor, mas também dos psicossociais e espirituais ${ }^{4}$.

A partir de tal compreensão ética de morte digna é possível afirmar que esta goza de proteção constitucional, conformando-se o direito à morte digna. Esse entendimento decorre do fato de a Constituição Federal de 1988 (CF) - portanto, a legislação infraconstitucional - ter sido erigida sobre os princípios fundamentais estabelecidos em seu art. $1^{\circ}$, que 
alicerça o princípio da dignidade da pessoa humana. $O$ texto constitucional relegou aos princípios fundamentais a condição de fundamentos da República, o que os tornou verdadeiros valores supremos da ordem jurídica. Nesses termos, a dignidade da pessoa humana é princípio fundamental que, como tal, não pode ser abandonado pelos atos do Estado e seus prepostos ${ }^{5}$.

Por sua relevância, a dignidade da pessoa humana permeia a interpretação de todo o sistema jurídico, inclusive da própria Constituição. Impossível falar em qualquer outro direito, mesmo direitos fundamentais, em termos que esvaziem aquele princípio fundamental. Nesse sentido, o direito à vida instituído pelo art. $5^{\circ}$, caput, $\mathrm{CF}$, deve ser interpretado sob a influência do princípio da dignidade humana: Todos são iguais perante a lei, sem distinção de qualquer natureza, garantindo-se aos brasileiros e estrangeiros residentes no País a inviolabilidade do direito à vida, à liberdade, à igualdade, à segurança e à propriedade, nos termos seguintes ${ }^{6}$. Desse modo, a conformação jurídica da morte digna ocorre por meio da proteção do direito à vida e do princípio fundamental da dignidade humana, porquanto a vida é fonte primária dos demais bens jurídicos ${ }^{7}$.

Ao abordar o direito à morte digna é comum que este seja rechaçado de plano por haver uma ideia de antagonismo frontal ante o direito à vida. Entende-se que ao resguardar a morte digna automaticamente se estaria impondo uma afronta à vida. Contudo, a morte digna que se entende resguardada constitucionalmente é aquela que integra o próprio direito à vida: a morte natural.

A morte nada mais é do que o fim natural do processo da vida. Não se trata de fenômeno alheio à vida, mas a ela intrínseco. $O$ direito à vida, como afirmado, não é um direito absoluto, vez que os princípios constitucionais, notadamente o princípio da dignidade humana, permeiam a interpretação de todos os direitos e garantias fundamentais. Assim, a vida protegida pela Constituição Federal é a vida digna. Pelo fato de a morte natural integrar a vida humana, conclui-se que ao proteger a vida o Constituinte protegeu também a morte digna, conformando esse valor em direito. Deste modo, enquanto há o direito à vida digna, pode-se igualmente falar em direito à morte digna.

Ante a definição ética de morte digna e a interpretação constitucional demonstrada, é possível concluir que o direito à morte digna é o direito de no fim da vida o indivíduo receber cuidados destinados à preservação de sua dignidade, do que decorre, além de outras consequências, o direito de optar pelo tratamento que julgar mais benéfico, mesmo que isso signifique não prolongar sua vida por meio de tratamentos extraordinários.

\section{Conceitos relacionados à morte digna}

Para melhor abordar a responsabilidade civil do médico, especificamente no caso da ortotanásia - assistência à morte natural, quando iminente e inevitável -, é necessário definir determinados conceitos referentes à terminalidade da vida usualmente confundidos entre si, que, contudo, conduzem a consequências jurídicas distintas. $O$ debate acerca da morte digna evidencia quatro principais condutas: a distanásia, o suicídio assistido, a eutanásia e a ortotanásia.

A distanásia, em regra, não envolve uma conduta do enfermo. Trata-se de um conjunto de tratamentos médicos que visam estender a sobrevida do paciente em fase terminal. Apesar de prolongar a vida do enfermo, a distanásia relega a segundo plano a qualidade de vida do paciente. Por tal motivo, é também conhecida como "obstinação terapêutica" 3. De fato, há pacientes que optam pela distanásia, mas a prática tornou-se quase que um tratamento padrão dispensado a pacientes em fase terminal de vida e sem participação na decisão do tratamento.

O suicídio assistido, em contrapartida, é uma das práticas que visam ao encurtamento da vida. 0 suicídio assistido se caracteriza por uma decisão da pessoa gravemente enferma que escolhe dar fim à própria vida. É a ação do próprio indivíduo que causa sua morte. Há, contudo, participação de um terceiro que $o$ auxilia de qualquer maneira, sob a forma de assistência material ou moral. No Brasil, o suicídio assistido é crime previsto pelo art. 122 do Código Penal (CP). A conduta do auxiliador será típica mesmo que a prática tenha ocorrido por sentimento de compaixão, não incidindo causa de diminuição de pena, como na hipótese da eutanásia ${ }^{8}$.

A necessidade da correta definição dos comportamentos que dizem respeito à terminalidade ganha destaque quando o suicídio assistido é comparado com a eutanásia. O elemento que distingue essas condutas, apesar de sutil, é fundamental para a adequação à correta consequência jurídica. A principal diferença entre o suicídio assistido e a eutanásia resta na pessoa cuja ação diretamente causará a morte. No suicídio assistido é o enfermo que causa a própria morte, sendo o auxiliador mero veículo para sua efetivação. Por sua vez, a eutanásia, como se verá, pressupõe que o ato que leva o paciente à 
morte seja praticado integralmente pelo terceiro, movido por compaixão.

A doutrina não apresenta conceito unânime de eutanásia: determinados autores entendem que apenas se considera eutanásia a morte promovida por médico; outros consideram a compaixão elemento caracterizador da eutanásia. Roberto Dias, em estudo jurídico acerca da eutanásia, entende que esta é a aceleração ou não prolongação da morte por motivo de compaixão promovida por médico a pedido expresso ou por vontade presumida do enfermo, mas sempre em seu interesse, levando-se em consideração sua compreensão de dignidade ${ }^{10}$.

Assim, a eutanásia é a prática que sempre parte de um terceiro, que, na acepção de Roberto Dias, sempre será um médico movido pela compaixão ao próximo. Pode ocorrer por ação ou omissão, acelerando a morte de um indivíduo acometido por grave doença incurável e que deseja dar fim ao próprio sofrimento. É exclusivamente a ação ou omissão do terceiro que ocasiona a morte do indivíduo.

A doutrina diferencia eutanásia ativa de eutanásia passiva. A eutanásia ativa consiste na ação de um terceiro que, por meio de conduta comissiva, põe fim à vida do enfermo - seu principal exemplo é a administração de drogas letais.

Quanto à eutanásia passiva, contudo, há divergência de entendimentos, apontando para consequências jurídicas distintas. Enquanto alguns, como Santoro ${ }^{8}$, consideram que a eutanásia passiva se caracteriza pela conduta omissiva que ocasionará a supressão ou a interrupção dos tratamentos indispensáveis à manutenção da vida do paciente, outros, representados por Diniz ${ }^{9}$, entendem que o mesmo conceito de eutanásia passiva é sinônimo de ortotanásia. Afasta-se a última tese por distinguirem a eutanásia - seja passiva ou ativa - e a ortotanásia quanto à causa da morte. Na eutanásia, ela será a ação/omissão de terceiro; na ortotanásia, a própria doença. Entende-se que a prática da eutanásia configura relevante valor moral, de forma a incidir a hipótese de diminuição da pena do crime de homicídio prevista no $\S 1^{\circ}$ do art. $121, \mathrm{CP}$ :

\section{Homicídio simples}

Art. 121. Matar alguém:

Pena - reclusão, de seis a vinte anos

Caso de diminuição de pena

$\S 1^{\circ}$ Se o agente comete o crime impelido por relevante valor social ou moral, ou sob o domínio de violenta emoção, logo em seguida a injusta provocação da vítima, o juiz pode reduzir a pena de um sexto a um terço ${ }^{11}$.
Verificando-se que a eutanásia constitui crime, para melhor distinção dos conceitos é importante demonstrar o que é a ortotanásia. Ante a constatação da inevitabilidade e da iminência da morte do paciente, suspendem-se os tratamentos agressivos, incapazes de beneficiá-lo e que lhe trazem dor e sofrimento no fim da vida. É necessário que o paciente - ou seu representante - consinta com a medida após receber informações claras a respeito do prognóstico e tratamentos disponíveis. A partir de sua concordância, passará a receber os cuidados paliativos.

Em regra, o paciente em fase terminal tem a possibilidade de optar pela distanásia - tratamentos extraordinários que possivelmente prolongarão o tempo de vida - ou pela ortotanásia. Logo, em oposição à distanásia, a ortotanásia adiantaria a morte, mas caso o paciente descarte a opção pelos tratamentos extraordinários e escolha a ortotanásia, a morte ainda ocorreria por evolução da enfermidade, em seu próprio ritmo, sem que fosse adiantado o tempo do óbito.

Contudo, a eticidade e a legalidade da prática da ortotanásia não se restringem ao adiantamento ou não da morte do paciente em fase terminal, mas se estendem à preservação da dignidade do indivíduo e do respeito à sua autonomia e declaração de vontade.

A ortotanásia constitui a humanização do processo da morte do paciente, cuidando para que o indivíduo no fim da vida encontre a morte com conforto e o mínimo de sofrimento possível, garantindo sua dignidade ${ }^{12}$. Consequentemente, ortotanásia e eutanásia passiva pouco têm em comum, pois não há indução da morte do paciente em fase terminal. Na ortotanásia a morte é inevitável e iminente, sendo suspensos os tratamentos inócuos à reversão do quadro do paciente.

A administração de cuidados paliativos afasta a teoria de que haveria omissão por parte dos profissionais de saúde, pois o paciente não é abandonado à própria sorte, pelo contrário, a ele são dispensados todos os cuidados para garantir seu bemestar, apesar da proximidade da morte. Conquanto a distanásia seja prática comum nos hospitais, aqueles em prol da ortotanásia defendem que a medicina deve se voltar para o bem-estar do paciente e manutenção de sua dignidade, revertendo o estado atual do tratamento médico dos pacientes em fase terminal, se esta for sua vontade manifesta.

\section{Elementos da responsabilidade civil}

Para que se conforme a responsabilidade civil é necessário que existam três elementos: culpa, 
dano e nexo de causalidade. A responsabilidade médica é, em regra, subjetiva, ou seja, depende da comprovação da culpa do profissional. O art. 951 do Código Civil traz três modalidades de culpa: negligência, imprudência e imperícia.

Art. 951. O disposto nos arts. 948, 949 e 950 aplicase ainda no caso de indenização devida por aquele que, no exercício de atividade profissional, por negligência, imprudência ou imperícia, causar a morte do paciente, agravar-lhe o mal, causar-Ihe lesão, ou inabilitá-lo para o trabalho ${ }^{13}$.

Considera-se negligência a omissão do médico com relação aos comportamentos recomendáveis pela prática ${ }^{14}$. Logo, haverá negligência médica quando o profissional, conhecedor das técnicas recomendáveis, deixa de aplicá-las a seu paciente, atua com desleixo ou, mesmo, o abandona à própria sorte, recomendando alta médica ou não realizando os exames necessários, entre variadas outras hipóteses.

A imprudência caracteriza-se por um ato comissivo do médico, que, por qualquer motivo, não toma as devidas cautelas - por ele conhecidas - ao tratar um paciente. Os cuidados e regras ignorados pelo médico imprudente existem para resguardar o paciente de possível empecilho que possa resultar no insucesso do procedimento. Portanto, ao ignorar esses cuidados instituídos pela prática, o médico assume o risco do insucesso.

Por fim, a imperícia é a falta de conhecimento ou habilitação técnica do médico.

O segundo elemento da responsabilidade civil é o dano, que advém de uma subtração de bem jurídico da esfera patrimonial ou extrapatrimonial de seu titular ${ }^{15}$. Sem o dano, mesmo havendo conduta antijurídica, seria impossível considerar a responsabilização do agente. A responsabilidade civil se presta a reequilibrar a situação entre as partes - devedor e credor. Se inexistente o prejuízo, inexistente também o desequilíbrio a ser restituído.

A reparação do dano é o objetivo da responsabilidade civil, apenas indenizável caso guarde certo grau de correlação com o ato culposo do médico omissivo ou comissivo. Tal correlação é o nexo de causalidade, terceiro elemento da responsabilidade civil. É o vínculo de causa e efeito que se estabelece entre o ato do médico - comissivo ou omissivo e o dano. O nexo de causalidade é essencial para a responsabilidade civil, porque mesmo havendo uma conduta culposa do médico, inclusive um dano ao paciente, não haverá hipótese de ressarcimento caso o dano experimentado não tenha decorrido daquela conduta culposa do médico, mas de uma complicação do estado de saúde do paciente, por exemplo.

\section{Responsabilidade civil do médico pela prática} da ortotanásia

Ao se considerar a hipótese de responsabilização de um médico que pratica a ortotanásia, é preciso ponderar no que ela consiste e quais elementos são necessários para a configuração da responsabilidade civil, pois o seu próprio conceito impede que se consolidem os elementos da responsabilidade civil.

Pontuou-se, com relação à ortotanásia, que seus elementos essenciais são: morte iminente e inevitável, administração de cuidados paliativos e consentimento informado do paciente. Quanto à responsabilidade civil, seus elementos são: culpa stricto sensu, dano e nexo de causalidade.

Ao praticar a ortotanásia o médico não estaria agindo com negligência, imperícia ou imprudência, em regra. Porque se pressupõe que, para que a ortotanásia se configure, é preciso que o médico avalie o prognóstico do paciente, preocupando-se com sua "qualidade de morte" e autonomia, converse sobre o fim da vida, tratamentos possíveis e administre cuidado paliativo.

Seria também impossível a consolidação do nexo de causalidade entre o ato do médico e a morte do paciente, visto que a ortotanásia refere-se a pacientes terminais. Assim, em razão da própria enfermidade, não há possibilidade de reversão do quadro do paciente. Há, sim, a possibilidade de prolongar sua vida, destituída, contudo, de qualidade e bem-estar. Nesse sentido, impossível atribuir o evento morte à conduta do médico que pratica a ortotanásia, especialmente porque ele não privou o paciente de cuidados essenciais, pelo contrário, afastou os cuidados inócuos à recuperação e administrou cuidados paliativos ${ }^{16}$.

É cediço que a morte imprevista e injustificada gera um dano indenizável, tanto moral quanto material, mas não é em toda e qualquer circunstância que deve ser considerada um dano. Hoje, é possível estender o fim da vida a duras penas, induzindo questionamentos relacionados à permissão para morrer. Não há violação de qualquer preceito jurídico se o médico, de acordo com o consentimento do paciente, suspende os tratamentos extraordinários e passa a administrar cuidados paliativos. É verdade que o consentimento do paciente é ineficaz quando versar sobre um comportamento ilícito, como o 
aborto ou o suicídio assistido. Entretanto, a ortotanásia é prática lícita, pois visa ao bem-estar do paciente em fase terminal - e a declaração de vontade que consentir a ortotanásia tem plena eficácia.

Por sua vez, o médico que vier a submeter um paciente a determinado tratamento contra sua vontade pratica o crime de constrangimento ilegal, salvo se o paciente correr risco de morte. Em termos de responsabilidade civil, paralelamente ao constrangimento ilegal previsto pela legislação penal, a atitude do médico que ignora a declaração de vontade do paciente terminal que em plenas faculdades mentais deseja recusar intervenções extraordinárias caracteriza, a nosso ver, negligência, podendo o profissional vir a ser responsabilizado civilmente.

\section{Considerações finais}

O presente estudo destinou-se à análise da responsabilidade civil do médico que pratica a ortotanásia, visando avaliar se o ato médico consistente no auxílio à morte digna do paciente terminal seria passível de responsabilização na esfera civil. Para tal, trabalhou-se essencialmente com levantamento doutrinário e jurisprudencial, mas, considerando-se que a ortotanásia é tema que se insere em diversos ramos, o estudo demandou pesquisa bibliográfica que extrapolou o direito civil, adentrando, por vezes, no direito constitucional, penal e ética.

Concluiu-se, enfim, que não há como responsabilizar civilmente o médico que pratica a ortotanásia, pois o seu próprio conceito impede a conformação dos elementos da responsabilidade civil. Ou seja, não há culpa, dano ou nexo de causalidade. Não há culpa, seja sob a forma de negligência, imprudência ou imperícia, porque a ortotanásia pressupõe a aplicação de cuidados paliativos e a preocupação com o bem-estar do paciente em fase terminal, ocorrendo, portanto, diligência (atenção à "qualidade de morte" do paciente), prudência (constatação da terminalidade do paciente e obtenção de seu consentimento informado) e conhecimento técnico (cuidados paliativos, que envolvem diversos ramos da medicina e outros a ela alheios).

Também não se pode falar em dano, pois não é sempre que a morte deve ser compreendida como dano. Dano é uma violação a um bem juridicamente protegido, que, no caso da morte, é a própria vida. Entretanto, como salientado, a morte não decorre necessariamente da interferência - ou omissão humana, inexistindo a configuração de dano em caso de morte natural. É, portanto, a causação da morte que constitui um dano, não a morte em si. A ortotanásia existe mediante consentimento livre e esclarecido do paciente no fim da vida, o que configura o atendimento do médico ao direito subjetivo do paciente escolher o próprio tratamento, não havendo comportamentos que ocasionem diretamente a morte. Trata-se, portanto, de comportamento ético do médico e de exercício do direito à autonomia do paciente.

Não há nexo de causalidade entre o ato do médico e a morte do paciente, pois a ortotanásia apenas existe relativamente a pacientes em fase terminal de vida, ou seja, a morte ocorre em razão da evolução da enfermidade, pois os tratamentos extraordinários seriam administrados para prolongar a quantidade da vida e os cuidados paliativos atuam na melhora da qualidade de vida.

Ainda em análise da responsabilidade civil do médico e da ortotanásia, foi possível alcançar conclusão adjacente. Ao rechaçar a declaração de vontade do paciente em fase terminal que requer a suspensão de tratamentos extraordinários, o médico age com culpa sob a forma de negligência, o que resulta em dano moral, pois feridas a dignidade e a autonomia do paciente, devendo o médico ser responsabilizado. Assim, entende-se que o médico que pratica a ortotanásia não pode ser responsável civilmente pelo ato em si ou pela consequente morte do paciente. Ao contrário, age de forma a garantir a autonomia do paciente com vistas à melhor qualidade de morte possível, em verdadeira realização do princípio da dignidade da pessoa humana.

Trabalho produzido na Faculdade de Medicina da Universidade de São Paulo (USP), São Paulo/SP, Brasil.

\section{Referências}

1. Conselho Federal de Medicina. Resolução $n^{\circ} 1.805$, de 9 de novembro de 2006. Na fase terminal de enfermidades graves e incuráveis é permitido ao médico limitar ou suspender procedimentos e tratamentos que prolonguem a vida do doente, garantindo-lhe os cuidados necessários para aliviar os sintomas que levam ao sofrimento, na perspectiva de uma assistência integral, 
respeitada a vontade do paciente ou de seu representante legal. [Internet]. 2006 (acesso 22 out. 2013). Disponível: http://www.portalmedico.org.br/resolucoes/CFM/2006/1805_2006.htm

2. Conselho Federal de Medicina. A ortotanásia na justiça brasileira. [Internet]. Revista Bioethikos. 2010 (acesso 22 out. 2013);4(4):476-86. Disponível: http://www.saocamilo-sp.br/pdf/ bioethikos/80/Bioethikos_476-486_.pdf

3. Forte DN. Associações entre as características de médicos intensivistas e a variabilidade no cuidado ao fim de vida em UTI. [tese]. [Internet]. São Paulo: Faculdade de Medicina da USP; 2011 (acesso 22 maio 2013). Disponível: http://www.teses.usp.br/teses/disponiveis/5/5169/tde07122011-124313/pt-br.php

4. Instituto Nacional de Câncer. Cuidados paliativos. [Internet]. (acesso 22 maio 2013). Disponível: http://www.inca.gov.br/conteudo_view.asp?ID=474

5. Silva JA. Comentário contextual à Constituição. $6^{a}$ ed. São Paulo: Malheiros; 2009. p. 38.

6. Brasil. Constituição da República Federativa do Brasil de 1988. [Internet]. 1988 (acesso 22 maio 2013). Disponível: http://www.planalto.gov.br/ccivil_03/Constituicao/Constituicao.htm

7. Silva JA. Op. cit. p. 66.

8. Santoro LF. Morte digna: o direito do paciente terminal. Curitiba: Juruá; 2010. p. 188.

9. Diniz MH. O estado atual do biodireito. $2^{\text {a }}$ ed. São Paulo: Saraiva; 2002. p. 840.

10. Dias R. O direito fundamental à morte digna: uma visão constitucional da eutanásia. Belo Horizonte: Fórum; 2012. p. 239.

11. Brasil. Decreto-lei $n^{\circ} 2.848$, de 7 de dezembro de 1940. [Internet]. Código Penal. 1940 (acesso 22 maio 2013). Disponível: http://www.planalto.gov.br/ccivil_03/decreto-lei/Del2848compilado. htm

12. Bostiancic MC, Dadalto L. Diretivas antecipadas para tratamentos médicos: um estudo comparado entre o direito brasileiro e o argentino. Mar del Plata: Universidad Nacional de Mar del Plata; 2010. p. 351.

13. Brasil. Lei $n^{\circ}$ 10.406, de 10 de janeiro de 2002. Código Civil. [Internet]. 2002 (acesso 22 maio 2013). Disponível: http://www.planalto.gov.br/ccivil_03/leis/2002/L10406compilada.htm

14. Kfouri Neto M. Responsabilidade civil do médico. $7^{\text {a }}$ ed. São Paulo: Editora Revista dos Tribunais; 2010. p. 652.

15. Lopez TA. O dano estético: responsabilidade civil. $2^{\mathrm{a}}$ ed. São Paulo: Editora Revista dos Tribunais; 1999. p. 125

16. Santoro LF. Op. cit. p. 147.

\section{Participação dos autores}

Maria Luiza Monteiro da Cruz trabalhou na concepção, análise e redação do artigo. Reinaldo Ayer participou da revisão crítica.

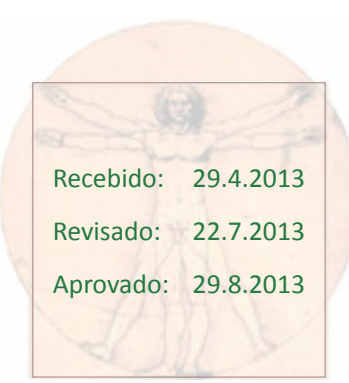

